\section{Commentary: If you have to simulate, do it well!}

\author{
Carlos A. Mestres, MD, PhD, FETCS, \\ Francesco Maisano, MD, FECS, ${ }^{a}$ and \\ Francis E. Smit, MD, PhD, FACC ${ }^{b}$
}

Simulation refers to a model of real activity created for training purposes or to solve a problem, situation, or event that seems real but is not real, used especially to help people dealing with such situations or events. ${ }^{1}$ Surgical simulation models have been in use for a long time. ${ }^{2}$ As we already highlighted, there is evidence that simulation in surgery provides a safe learning environment and allows for adaptations to suit individual/unit requirements or specific diseases or approaches. ${ }^{3}$

Teaching and learning surgery of the mitral valve are not easy tasks because of the complex anatomy, uncomfortable surgical access, exposure in repair techniques, and a steep learning curve. Using diverse simultaneous techniques when attempting repair makes the process certainly cumbersome. ${ }^{4,5}$

In this issue of the Journal, Imbrie-Moore and colleagues ${ }^{6}$ describe the design of a disease model that accurately simulates the morphology and pathophysiology of Barlow's disease. The authors developed a cross-species ex vivo model. Bovine mitral valves were sewn into a porcine annulus mount to create excess leaflet tissue. The authors used a heart simulator to generate physiologic pressures and flows. The model successfully imitated the complexities of Barlow's disease, and they repaired the valves with nonresectional techniques. The reported hemodynamics confirmed the restoration physiology and reduction of valve regurgitation. The authors concluded that their study provides insight into the biomechanics of Barlow's

From the ${ }^{\mathrm{a} C l i n i c}$ for Cardiac Surgery, University Hospital Zürich, Zürich, Switzerland; and ${ }^{\mathrm{b}}$ Department of Cardiothoracic Surgery, the University of the Free State, Bloemfontein, South Africa.

Disclosures: Authors have nothing to disclose with regard to commercial support.

Received for publication Jan 19, 2020; accepted for publication Jan 21, 2020; available ahead of print Feb 8, 2020.

Address for reprints: Carlos A. Mestres, MD, PhD, FETCS, Clinic for Cardiac Surgery, University Hospital Zürich, Rämistrasse 100, CH-8091 Zürich, Switzerland (E-mail: Carlos.Mestres@usz.ch).

J Thorac Cardiovasc Surg 2021;161:1786-7

$0022-5223 / \$ 36.00$

Copyright (c) 2020 by The American Association for Thoracic Surgery

https://doi.org/10.1016/j.jtcvs.2020.01.056

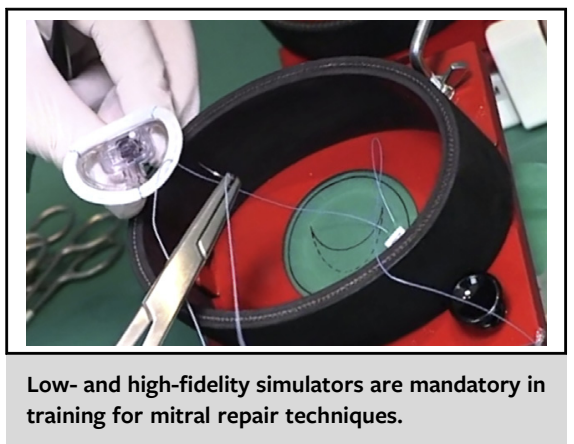

CENTRAL MESSAGE

This article highlights the development of a cross-species, ex vivo, high-fidelity model that allows for successful simulation and analysis of Barlow's valve repair techniques in a risk-free environment.

disease. An extensive literature search confirms that this is a unique model for training in mitral valve surgery.

This is a complex model because the authors combined different topics to replicate a complex disease. The mounting ring and the left heart simulator were 3-dimensionally printed. They adjusted the displacement of the papillary muscles to influence the regurgitant fraction. Their simulated analyses addressed valve leaking volume and measurements for chordal force. Overall, this is an attractive model.

Simulation is of great interest for the community. Lowand high-fidelity simulation models to recreate complex situations are needed. Daemen and colleagues ${ }^{7}$ and Sardari Nia and colleagues ${ }^{8}$ have also used modeling and rapid protoyping for the production of mitral replications useful in surgical simulation. Imbrie-Moore and colleagues ${ }^{6}$ confirm that the simulated repair addresses multisegmental and bileaflet lesions. There may be discussions about this model's ability to entirely replicate the complexity of Barlow's disease and if regurgitation was partially or completely eliminated. Although this model is a complex system with a limited number of simulated repairs, it may be useful not only in the setting of redundant valves but also in any type of mitral disease. Furthermore, it could provide data on resectional or nonresectional repair techniques. It may also provide a useful and versatile simulation platform in which transcatheter repair technology and techniques could be evaluated, as is surely contemplated by the authors. 
Every tool is welcome, but the ultimate quality of simulation models counts. Apart from the obvious application in research and development, high-quality simulation models will become essential in developing high-quality integrated interdisciplinary simulation programs, allowing for the stepwise development of proficiency in the surgical trainee in a risk-free environment. ${ }^{3}$

\section{References}

1. Cambridge Dictionary. Simulation. Available at: https://dictionary.cambridge.org. Accessed January 15, 2020

2. Seymour NE. VR to OR: a review of the evidence that virtual reality simulation improves operating room performance. World J Surg. 2008;32:182-8.
3. Smit FE, Jones TJ, Mestres CA, Sadaba JR, Pillay J, Yankah C, et al. Integrated interdisciplinary simulation programmes: an essential addition to national and regional cardiothoracic surgical training and education programmes. Eur J Cardiothorac Surg. 2019;55:811-6.

4. Sündermann SH, Falk V, Jacobs S. Mitral valve reconstruction - timing, surgical techniques and results. Swiss Med Wkly. 2012;142:w13715.

5. De Bonis M, Maisano F, La Canna G, Alfieri O. Treatment and management of mitral regurgitation. Nat Rev Cardiol. 2011;9:133-46.

6. Imbrie-Moore AM, Paulsen MJ, Zhu Y, Wang H, Lucian HJ, Farry JM, et al. A novel cross-species model of Barlow's disease to biomechanically analyze repair techniques in an ex vivo left heart simulator. J Thorac Cardiovasc Surg. 2021;161:1776-83.

7. Daemen JHT, Heuts S, Olsthoorn JR, Maessen JG, Sardari Nia P. Mitral valve modelling and three-dimensional printing for planning and simulation of mitral valve repair. Eur J Cardiothorac Surg. 2019;55:543-51.

8. Sardari Nia P, Daemen JHT, Maessen JG. Development of a high-fidelity minimally invasive mitral valve surgery simulator. J Thorac Cardiovasc Surg. 2019; $157: 1567-74$ 